\title{
Traditional and Nontraditional Cardiovascular Risk Factors and Estimated Risk for Coronary Artery Disease in Renal Transplant Recipients: A Single-Center Experience
}

\author{
Miriam C. Banas ${ }^{a} \quad$ Bernhard Banas ${ }^{a}$ Stephan R. Orth ${ }^{a, c} \quad$ Veronika Langer $^{a}$ \\ Stephan W. Reinhold ${ }^{a}$ Christian Weingart ${ }^{a}$ Bettina Jung ${ }^{a}$ Bernd Krüger $^{b}$ \\ Bernhard K. Krämer ${ }^{\text {b }}$

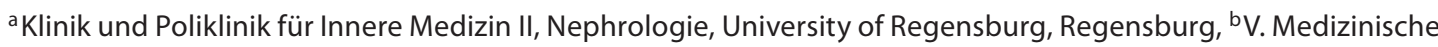 \\ Klinik, University Hospital of Mannheim, Mannheim and ' Dialysis Center Bad Aibling, Bad Aibling, Germany
}

\section{Key Words}

Hypertension · Smoking • Hyperlipidemia • Diabetes •

Risk factor control $\cdot$ Immunosuppression $\cdot$ Kidney

transplantation $\cdot$ Statins

\begin{abstract}
Background/Aims: The prevalence of cardiovascular disease in renal transplant recipients is markedly higher than in the general population due to the high prevalence of traditional cardiovascular risk factors, renal transplant function impairment and treatment with immunosuppressive drugs that affect blood pressure, cholesterol and blood glucose levels. Methods: Cross-sectional analysis using our renal transplant clinic cohort investigating (1) the cardiovascular risk factors present in this cohort, and (2) estimating their impact on the risk of coronary artery disease (CAD) by using the Framingham algorithm. Results: Control of modifiable cardiovascular risk factors in 231 renal transplant recipients is suboptimal, i.e. $47.2 \%$ of patients are hypertensive, $10.3 \%$ actively smoke, $39.4 \%$ have serum cholesterol concentrations $>200 \mathrm{mg} / \mathrm{dl}$, and $19.7 \%$ have diabetes mellitus. Blood pressure, age, hyperlipidemia, smoking and diabetes modulate the estimated CAD risk in males and females. Further-
\end{abstract}

more, a short time period (less than 1 year) since transplantation and increased serum creatinine levels negatively influenced the CAD risk in this patient population. Conclusion: According to current guidelines, the control of modifiable cardiovascular risk factors in renal transplant recipients is suboptimal. The decreasing CAD risk over time after transplantation may be due to the reduction of immunosuppressive drugs with time and survival bias.

Copyright $\odot 2011$ S. Karger AG, Basel

\section{Introduction}

With improvements in surgical techniques, HLA matching and immunosuppression, renal transplantation has become the treatment of choice for patients with end-stage renal disease. Despite the advances in transplantation and the improvements in short-term transplant survival there is increasing concern about the deleterious effects of post-transplantation complications on long-term survival. Death with a functioning graft is accounting for half of the graft losses in the first 5 years after transplantation. Cardiovascular events are the most common causes of death after renal transplantation, with

\section{KARGER}

Fax +41613061234 E-Mail karger@karger.ch www.karger.com
(C) 2011 S. Karger AG, Basel

$1660-2110 / 11 / 1193-0227 \$ 38.00 / 0$

Accessible online at:

www.karger.com/nec
Dr. Miriam C. Banas

Klinik und Poliklinik für Innere Medizin II - Nephrologie

University of Regensburg

DE-93042 Regensburg (Germany)

Tel. +49941944 7301, E-Mail miriam.banas@klinik.uni-regensburg.de 
cerebrovascular disease, myocardial infarction, and other cardiac events accounting for approximately $40 \%$ of deaths, followed by infections and malignancies [1].

The prevalence of cardiovascular disease (CVD) in renal transplant recipients is significantly higher than in the general population. Prevalence of coronary artery disease (CAD) and left ventricular hypertrophy is approximately 15 and $50 \%$, respectively [2]. The high prevalence of CAD is partly explained by traditional cardiovascular risk factors such as hypertension, hyperlipidemia, smoking and diabetes mellitus [3-7]. In addition, risk factors that are specific to the situation of renal insufficiency or damage, e.g. proteinuria, chronic inflammation, increased oxidative stress, thrombogenic factors, hyperhomocysteinemia and anemia, may affect the incidence of CVD in both chronic renal failure and end-stage kidney disease $[2,8]$. Moreover, it has been documented that immunosuppressive drugs may modulate the estimated risk of CAD by affecting blood pressure, cholesterol and blood glucose in transplant patients [9].

In the present cross-sectional study, we investigated all renal transplant patients that were followed consecutively in our renal transplant clinic in 2004. Data about traditional cardiovascular risk factors (i.e. age, blood pressure, total cholesterol, smoking status, presence or absence of diabetes mellitus) as well as nontraditional cardiovascular risk factors playing a potential role after kidney transplantation (i.e. immunosuppressive therapy, duration of dialysis prior to transplantation, renal transplant function, antihypertensive therapy and time elapsed since transplantation) were collected. The 10 -year risk of CAD was estimated with the algorithm proposed by Wilson et al. [10] in the Framingham study.

\section{Patients and Methods}

\section{Patient Characteristics}

In 2004, a total of 231 consecutive patients (144 men and 87 women) were followed at the transplantation center of the University Hospital of Regensburg, Germany. The subjects of this cohort had been transplanted between 1986 and 2003 and were included into the present cross-sectional study. The study was done in accordance with the rules of the local ethics committee and the Declaration of Helsinki for clinical studies.

A medical history was taken and a physical examination was performed by a nephrologist. Variables included in the analysis were recipient age, gender, ethnicity, body weight, body mass index (weight in kilograms divided by height in square meters), cause of renal failure (type 1 or type 2 diabetes, nephrosclerosis including hypertension and renovascular disease, primary glomerulonephritis, polycystic kidney disease, systemic lupus erythematosus, other causes), time on dialysis before transplanta- tion, kidney transplant from a living or deceased donor, presence or absence of diabetes mellitus and hypertension, as well as smoking status.

\section{Blood Pressure}

Two blood pressure measurements were done with a sphygmomanometer from ERKA (Bad Tölz, Germany) after the participant had been sitting for at least $5 \mathrm{~min}$, and the mean of both measurements was used for analysis. Hypertension was categorized according to the JNC-7 definition [11]: normal (systolic $<120 \mathrm{~mm} \mathrm{Hg}$ and diastolic $<80 \mathrm{~mm} \mathrm{Hg}$ ), prehypertension (systolic $120-139 \mathrm{~mm} \mathrm{Hg}$ or diastolic $80-89 \mathrm{~mm} \mathrm{Hg}$ ), hypertension stage 1 (systolic $140-159 \mathrm{~mm} \mathrm{Hg}$ or diastolic 90-99 $\mathrm{mm} \mathrm{Hg}$ ), hypertension stage 2 (systolic $\geq 160 \mathrm{~mm} \mathrm{Hg}$ or diastolic $\geq 100$ $\mathrm{mm} \mathrm{Hg}$ ). When systolic and diastolic pressures fell into different categories, the higher category was selected for the purpose of classification.

\section{Diabetes Mellitus}

According to the Framingham study, diabetes mellitus was considered present if the participant was under treatment with insulin or oral hypoglycemic agents, if casual blood glucose levels exceeded $150 \mathrm{mg} / \mathrm{dl}$ at two clinic visits or if fasting blood glucose levels exceeded $140 \mathrm{mg} / \mathrm{dl}[10]$.

\section{Laboratory Values}

Venous blood was drawn after overnight fast, and serum creatinine, HbAlc, total cholesterol, high-density lipoprotein (HDL), low-density lipoprotein (LDL) and triglycerides were measured by standard laboratory techniques. These parameters were used to subdivide the patient cohort into different categories: total cholesterol $(<160,160-199,200-239,240-279$, and $\geq 280 \mathrm{mg} /$ $\mathrm{dl})$, HDL $(<35,35-59$, and $\geq 60 \mathrm{mg} / \mathrm{dl})$, LDL $(<130,130-159$, and $\geq 160 \mathrm{mg} / \mathrm{dl})$, and serum creatinine $(<1.5,1.5-3.0$, and $>3.0$ $\mathrm{mg} / \mathrm{dl})$.

\section{Medication}

Current medication including immunosuppressive drugs, antihypertensive medication (beta-blockers, ACE inhibitors, diuretics, angiotensin receptor blockers and calcium antagonists), cardiac glycosides, anticoagulants, insulin, oral hypoglycemic agents and statins was assessed in all patients.

\section{Estimation of CAD Risk}

To estimate the 10-year risk for CAD events in our patient cohort, we used the established algorithm proposed by Wilson et al. [10] in the Framingham study. This algorithm consists of classical cardiovascular risk factors as follows: systolic/diastolic blood pressure, total cholesterol, HDL cholesterol, smoking status, presence or absence of diabetes mellitus, as well as age and gender.

\section{Statistical Analysis}

Results are expressed as mean \pm SEM, unless stated otherwise. Comparisons of continuous variables between groups were performed by nonparametric tests, comparisons of categorical variables by two-sided $\chi^{2}$ or two-sided Fisher's exact test where applicable. SPSS version 12 software package (SPSS Inc., Chicago, Ill., USA) was used for statistical analysis. 


\section{Results}

The patient characteristics are shown in table 1. All 231 patients enrolled were Caucasians, 144 were males and 87 were females. Age did not differ between gender $(51.3 \pm 12.5$ years in males and $51.3 \pm 13.8$ years in $\mathrm{fe}$ males). The main cause of renal failure in males was glomerulonephritis $(\mathrm{n}=48)$ followed by diabetes $(\mathrm{n}=18)$ and polycystic kidney disease $(\mathrm{n}=10)$. In females, the main cause of renal failure was glomerulonephritis $(n=16)$ followed by reflux nephropathy $(\mathrm{n}=10)$ and other diseases (lupus erythematosus, tuberculosis, sarcoidosis, oxalosis, distal tubular acidosis, ANCA-positive small vessel vasculitis). The percentage of living donor transplants was $27 \%$ in males versus $19 \%$ in females. Time since transplantation was $38.0 \pm 47.5$ months in males and $49.0 \pm$ 39.0 months in females. Dialysis time before transplantation was on average 4 years in both males (range 0-14 years) and females (range $0-13$ years). Significant differences between males and females were found concerning serum creatinine concentrations $(1.9$ vs. $1.7 \mathrm{mg} / \mathrm{dl}$, p < $0.05)$, body mass index ( 26.3 vs. $25.1, \mathrm{p}<0.05)$, HDL cholesterol (43 vs. $52 \mathrm{mg} / \mathrm{dl}, \mathrm{p}=0.005)$, LDL cholesterol (105 vs. $96 \mathrm{mg} / \mathrm{dl}, \mathrm{p}<0.05)$ and the number of antihypertensive drugs $(2.4$ vs. $1.9, \mathrm{p}<0.01)$. The other patient characteristics investigated did not significantly differ between genders (table 1).

\section{CAD Risk and Age}

The 10-year CAD risk was calculated using the formula established in the Framingham study [10]. The average CAD risk was significantly higher in males as compared to females, i.e. $12.6 \pm 8.7$ vs. $8.6 \pm 8.7 \%(\mathrm{p}<0.01)$. In the present cohort, renal transplant recipients younger than 30 years of age had a very low risk of developing CAD within the next 10 years (males $2.8 \pm 0.5 \%$, females $0.4 \pm 0.1 \%$ ). CAD risk rises with increasing age. This is even more evident in males as compared to females. $\mathrm{Pa}$ tients aged $\geq 71$ years exhibit the highest CAD risk, i.e. $28.7 \pm 2.7 \%$ in males and $14.4 \pm 3.0 \%$ in females $(\mathrm{p}<$ 0.01 ). Whereas males $<50$ years and $>61$ years show a higher risk of $\mathrm{CAD}$ compared to females in the respective age groups, the CAD risk in the 51-60 years age category is equal in males and females (fig. 1; table 2).

\section{CAD Risk, Blood Pressure and Antihypertensive Medication}

Hypertension plays a pivotal role for CAD risk and due to both pre-existing hypertension and immunosuppressive therapy renal transplant recipients often have
Table 1. Patient characteristics of renal transplant recipients

\begin{tabular}{|c|c|c|c|}
\hline & $\begin{array}{l}\text { Male } \\
(\mathrm{n}=144)\end{array}$ & $\begin{array}{l}\text { Female } \\
(\mathrm{n}=87)\end{array}$ & $\mathrm{p}$ \\
\hline Age, years & $51.3 \pm 12.5$ & $51.3 \pm 13.8$ & 0.49 \\
\hline Body mass index & $26.3 \pm 3.9$ & $25.1 \pm 4.8$ & 0.02 \\
\hline Living donor, $\%$ & 27.0 & 19.0 & 0.13 \\
\hline Dialysis duration, years & $4.0(0-14)$ & $4.0(0-14)$ & 0.13 \\
\hline Current smoking, $\%$ & 9.0 & 12.6 & 0.2 \\
\hline Hypertension (\%) after Tx & 47.2 & 47.1 & 0.41 \\
\hline $\begin{array}{l}\text { Mean systolic blood pressure } \\
\text { mm Hg }\end{array}$ & $138 \pm 14$ & $139 \pm 19$ & 0.26 \\
\hline $\begin{array}{l}\text { Mean diastolic blood pressure } \\
\text { mm Hg }\end{array}$ & $79 \pm 11$ & $81 \pm 12$ & 0.18 \\
\hline Total cholesterol, mg/dl & $197 \pm 48$ & $197 \pm 40$ & 0.14 \\
\hline HDL cholesterol, mg/dl & $43 \pm 18$ & $52 \pm 15$ & 0.005 \\
\hline LDL cholesterol, mg/dl & $105 \pm 34$ & $96 \pm 29$ & 0.04 \\
\hline Triglycerides, mg/dl & $203 \pm 148$ & $192 \pm 113$ & 0.39 \\
\hline Creatinine, mg/dl & $1.9 \pm 0.8$ & $1.7 \pm 0.8$ & 0.01 \\
\hline Blood glucose, mg/dl & $110 \pm 36$ & $109 \pm 109$ & 0.37 \\
\hline HbAlc, $\%$ & $5.1 \pm 2.0$ & $5.3 \pm 1.8$ & 0.3 \\
\hline $\begin{array}{l}\text { Time since transplantation } \\
\text { months }\end{array}$ & $38 \pm 47.5$ & $49 \pm 39.0$ & 0.2 \\
\hline $\begin{array}{l}\text { Numbers of antihypertensive } \\
\text { medication }\end{array}$ & $2.4 \pm 1.4$ & $1.9 \pm 1.2$ & 0.002 \\
\hline Statin, \% & 46.5 & 54.2 & 0.41 \\
\hline
\end{tabular}

Data are shown as mean values \pm SEM.

elevated blood-pressure. Despite the fact that $90.4 \%$ of the patients enrolled in this study received antihypertensive treatment, only 122 of the 231 patients (i.e. $52.8 \%$ ) had normal blood pressure. In males [females] the CAD risk significantly increases from $9.4 \pm 1.5 \%[4.3 \pm$ $1.0 \%]$ in patients with normal blood pressure to $18.7 \pm$ $1.2 \%[12.6 \pm 2.2 \%]$ in patients with hypertension stage 2 ( $p<0.01)$. As compared to males, females show a lower risk of CAD throughout all blood pressure categories (fig. 1; table 3). The mean number of antihypertensive drugs is $2.4 \pm 1.4$ in males and $1.9 \pm 1.2$ in females ranging in males from $0(n=9)$ to $6(n=1)$ drugs and in females from $0(n=13)$ to $5(n=3)$ drugs. In males the CAD risk significantly increases from $7.9 \pm 2.0 \%$ in males without antihypertensive medication to $15.3 \pm$ $3.3 \%$ with 4 antihypertensive drugs $(\mathrm{p}<0.01)$. In females the CAD risk increases from $4.5 \pm 1.8 \%$ without antihypertensive treatment to $11.4 \pm 0.5 \%$ with 5 drugs, whereas statistical significance was only reached in comparison with 3 antihypertensive drugs $(11.0 \pm 2.0$, $\mathrm{p}<0.01)$.

Nephron Clin Pract 2011;119:c227-c235

CAD and Risk Factors in Renal 
Fig. 1. Estimated risk for CAD and its relationship to traditional cardiovascular risk factors. ${ }^{*} \mathrm{p}<0.05,{ }^{* *} \mathrm{p}<0.01$.
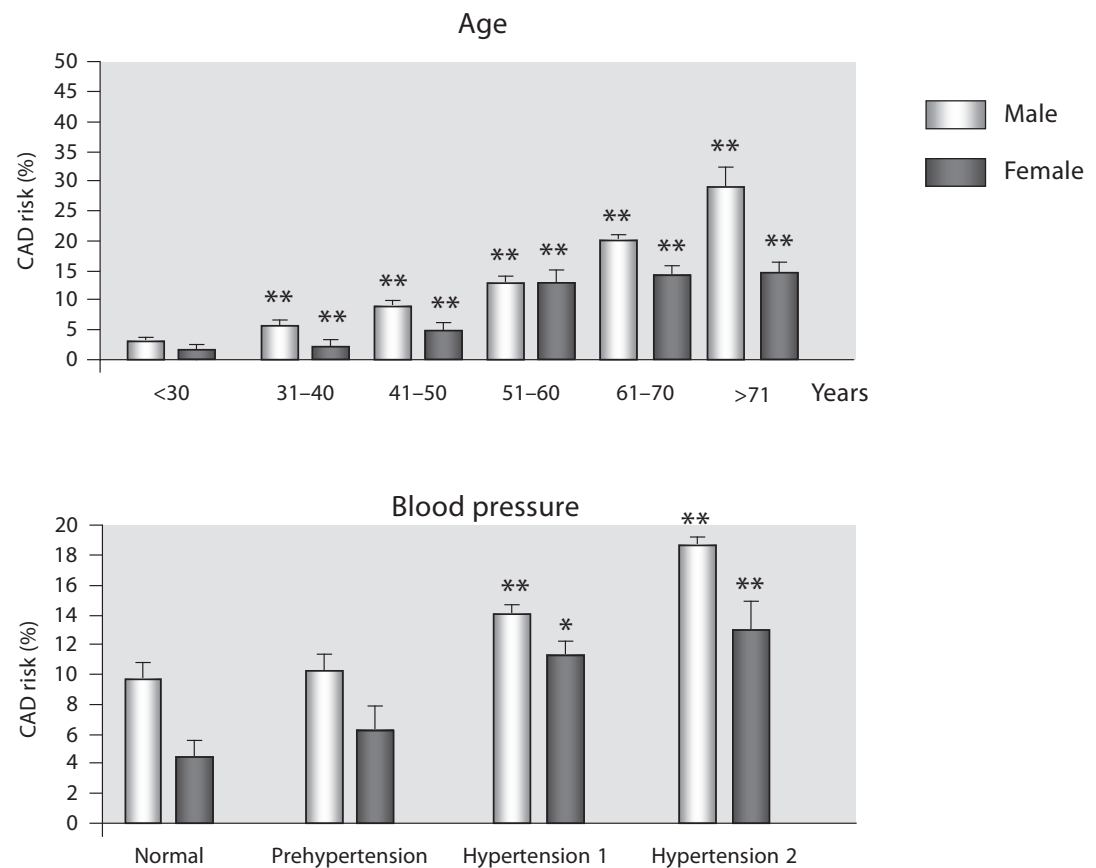

Total cholesterol
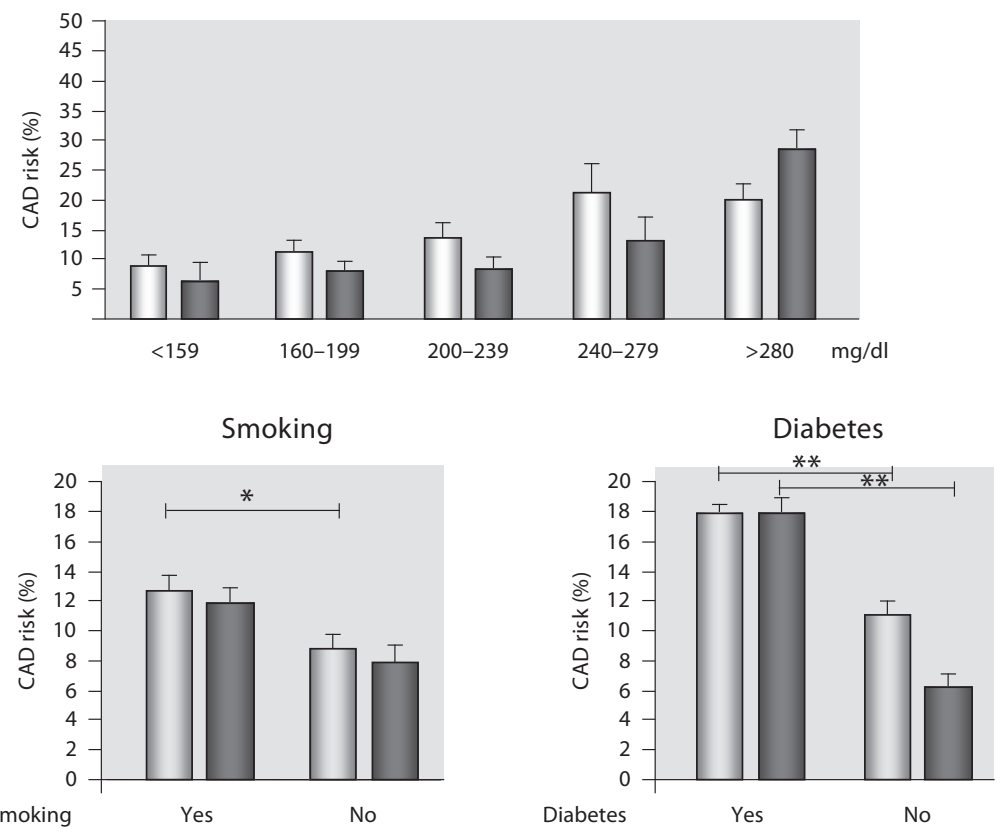

CAD risk increases with increasing cholesterol levels. Male [female] patients with serum cholesterol concentrations $<159 \mathrm{mg} / \mathrm{dl}$ show a CAD risk of $8.2 \pm 1.3 \%$ [6.8 \pm $2.5 \%$. Total serum cholesterol levels $>280 \mathrm{mg} / \mathrm{dl}$ are associated with a tendency to a higher CAD risk in females 
Table 2. CAD risk in \% based on the Framingham risk score in transplanted males and females according to age

\begin{tabular}{lrr}
\hline Age & \multicolumn{1}{c}{ Males } & \multicolumn{1}{c}{ Females } \\
\hline$<30$ years & $2.8 \pm 0.5$ & $0.4 \pm 0.1$ \\
31-40 years & $6.4 \pm 1.0$ & $1.6 \pm 0.3$ \\
$41-50$ years & $8.4 \pm 0.7$ & $4.6 \pm 1.4$ \\
$51-60$ years & $13.2 \pm 1.0$ & $12.7 \pm 1.8$ \\
61-70 years & $19.8 \pm 1.4$ & $14.2 \pm 1.9$ \\
$>71$ years & $28.7 \pm 2.7$ & $14.4 \pm 3.0$ \\
\hline
\end{tabular}

Data are shown as mean values \pm SEM.

Table 3. CAD risk in transplanted males and females according to blood pressure

\begin{tabular}{lrr}
\hline Blood pressure & \multicolumn{1}{c}{ Males } & Females \\
\hline Normal & $9.4 \pm 1.5$ & $4.3 \pm 1.0$ \\
Prehypertension & $10.3 \pm 1.3$ & $6.5 \pm 1.0$ \\
Hypertension stage 1 & $14.3 \pm 1.2$ & $11.0 \pm 1.6$ \\
Hypertension stage 2 & $18.7 \pm 1.2$ & $12.6 \pm 2.2$ \\
\hline
\end{tabular}

Data are shown as mean values \pm SEM. The blood pressure definitions are based on JNC-7 definitions.

Table 4. CAD risk in transplanted males and females according to total cholesterol

\begin{tabular}{lrr}
\hline Cholesterol & \multicolumn{1}{c}{ Males } & \multicolumn{1}{c}{ Females } \\
\hline$<159 \mathrm{mg} / \mathrm{dl}$ & $8.2 \pm 1.3$ & $6.8 \pm 2.5$ \\
$160-199 \mathrm{mg} / \mathrm{dl}$ & $10.3 \pm 1.0$ & $8.0 \pm 1.0$ \\
$200-239 \mathrm{mg} / \mathrm{dl}$ & $14.4 \pm 1.5$ & $8.0 \pm 1.2$ \\
$240-279 \mathrm{mg} / \mathrm{dl}$ & $21.4 \pm 5.3$ & $11.8 \pm 4.5$ \\
$>280 \mathrm{mg} / \mathrm{dl}$ & $17.5 \pm 0.7$ & $28.3 \pm 4.4$ \\
\hline
\end{tabular}

Data are given as mean values \pm SEM.

(28.3 $\pm 4.4 \%)$ as compared to males (17.5 $\pm 0.7 \%)$, although this gender difference did not reach statistical significance (fig. 1; table 4). A significant difference could be seen when comparing HDL- and LDL-cholesterol levels, however. The CAD risk in male [female] patients with a HDL-cholesterol less than $35 \mathrm{mg} / \mathrm{dl}$ is significantly higher $(13.9 \pm 1.7 \%[13.0 \pm 5.6 \%])$ than in patients with HDL levels $\geq 60 \mathrm{mg} / \mathrm{dl}(5.2 \pm 0.3 \%$ [4.6 $\pm 1.0 \%](\mathrm{p}<0.001$ $[\mathrm{p}<0.01]))$. Male [female] patients with a LDL-cholester- ol $>160 \mathrm{mg} / \mathrm{dl}$ have also a significantly increased CAD risk of $17.3 \pm 2.6 \%$ [18.6 $\pm 6.3 \%]$ compared to patients with LDL levels $<130 \mathrm{mg} / \mathrm{dl}(11.4 \pm 0.8 \%$ [8.3 $\pm 1.1 \%])$ $(\mathrm{p}<0.05[\mathrm{p}<0.001])$.

Treatment with statins lowers significantly the risk of CAD in males (with treatment: CAD risk $11.6 \pm 1.1 \%$; without treatment: CAD risk $13.8 \pm 1.0 \%, \mathrm{p}<0.05)$ and females (with treatment: CAD risk $5.9 \pm 1.1 \%$; without treatment: CAD risk $11.0 \pm 1.4 \%, \mathrm{p}<0.01$ ) (fig. 2).

\section{CAD Risk and Diabetes Mellitus}

Of the 231 patients, 46 (19.7\%) had diabetes mellitus. The mean HbAlc in patients with diabetes mellitus was $6.5( \pm 1.1 \%)$ in males and $6.2( \pm 0.7 \%)$ in females. CAD risk significantly increases in patients with diabetes mellitus in both males and females. Whereas the risk of CAD was $11.2( \pm 0.8 \%)$ in males without diabetes, it was substantially higher in males with diabetes mellitus, i.e. 17.9 $( \pm 1.0 \% ; \mathrm{p}<0.001)$. The negative impact of diabetes mellitus was also evident in the female population: in females with diabetes mellitus the risk of CAD was 17.8 ( $\pm 1.9 \%)$, in those without diabetes it was substantially lower, i.e. $6.3( \pm 0.7 \%$; $<<0.001)$ (fig. 1$)$.

\section{Smoking and CAD Risk}

Smoking is a strong risk factor for the development of CVD and also worsens kidney function. Of the 231 patients, 24 (10.3\%) were smokers. Serum creatinine concentrations in this study showed no differences between smokers and nonsmokers (male smokers $2.0 \mathrm{mg} / \mathrm{dl}$ $( \pm 0.9)$, nonsmokers $1.9 \mathrm{mg} / \mathrm{dl}( \pm 0.8)$; female smokers 1.8 $\mathrm{mg} / \mathrm{dl}( \pm 0.9)$, female nonsmokers $1.7 \mathrm{mg} / \mathrm{dl}( \pm 0.7)$ ). Smoking is significantly associated with an increased CAD risk in males [smokers $12.9( \pm 0.7 \%)$, nonsmokers $9.7( \pm 0.8 \%)(\mathrm{p}<0.05)$ ], but not in females [smokers 11.9 $( \pm 0.9 \%)$, nonsmokers $8.0( \pm 0.8 \%)(\mathrm{p}=0.06)]$ (fig. 1$)$.

\section{Effects of Time-Depending Variables (Prior and}

Post-Transplant) and Renal Function on CAD Risk

Since improvement or normalization of renal function after transplantation is known to influence CAD risk positively and change of renal function is time dependent after transplantation, we both analyzed the impact of renal function on the CAD risk score, and the time from transplantation, as well as time on dialysis, respectively.

\section{Creatinine Levels}

If renal function is categorized into 3 groups $(<1.5$; $1.5-3 ;>3.0 \mathrm{mg} / \mathrm{dl}$ ) in males and females, the average CAD risk score is increasing with lower renal function, but this 


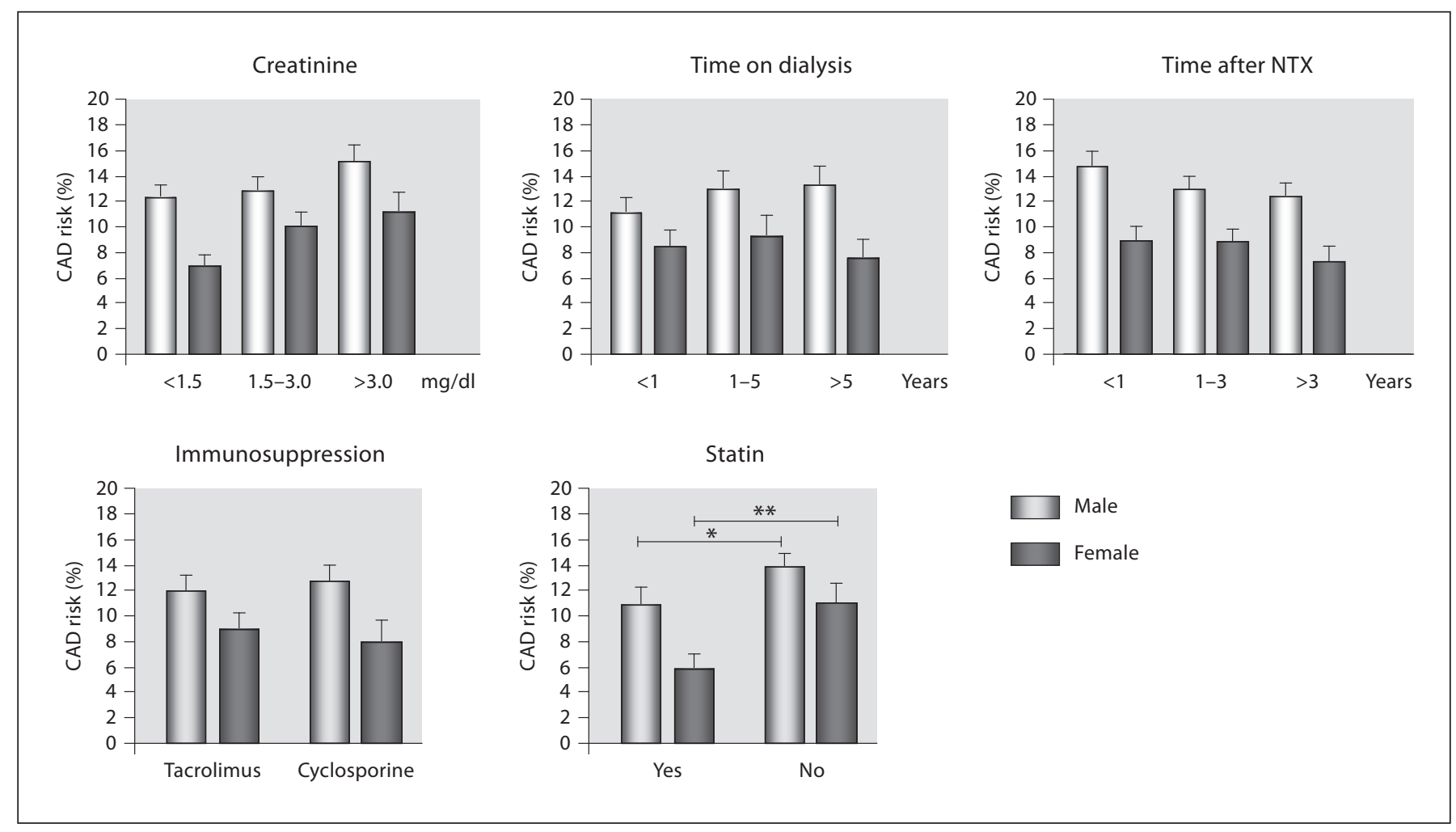

Fig. 2. Estimated risk for $\mathrm{CAD}$ and its relationship to additional cardiovascular risk factors. ${ }^{*} \mathrm{p}<0.05,{ }^{* *} \mathrm{p}<0.01$.

does not reach statistical significance $(<1.5 \mathrm{mg} / \mathrm{dl}: 12.0 \pm$ $1.3 \%$ (males) vs. $7.7 \pm 1.2 \%$ (females); $1.5-3 \mathrm{mg} / \mathrm{dl}: 12.7$ \pm 1.1 vs. $10.4 \pm 1.7 \% ;>3 \mathrm{mg} / \mathrm{dl}: 15.0 \pm 1.5$ vs. $11.6 \pm$ $1.1 \%)$. Further, no correlation with CAD risk could be seen if crude serum creatinine levels were analyzed (males: $\mathrm{r}^{2}=0.02, \mathrm{p}=0.12$; females: $\mathrm{r}^{2}=0.004, \mathrm{p}=0.55$ ).

\section{Time Post-Transplant}

To assess the relevance between the time since transplantation and the CAD risk score, we performed two different approaches. First, we grouped our patient cohort according to their time post-transplant: $<1$ year, $1-3$ years, and $>3$ years post-transplant, and second we correlated the time post-transplant with the CAD score. We could not detect any association neither after grouping the patients, nor if we correlated the time post-transplant with the CAD score (males: $\mathrm{r}^{2}=0.003,(\mathrm{p}=0.55)$ : females: $\left.r^{2}=0.0003, p=0.87\right)$. However, the CAD score seems to be slightly reduced (n.s.) over time ( $<1$ year: $14.6 \pm 2.1$ vs. $9.5 \pm 1.8 \%$ (males vs. females); $1-3$ years: $12.4 \pm 1.1$ vs. $9.6 \pm 1.8 \%,>3$ years $12.2 \pm 0.9$ vs. $7.5 \pm$ $1.1 \%)$.

\section{CAD Risk and Time on Dialysis}

Time on dialysis prior to transplantation is not associated with a significant increase in CAD risk, neither after grouping the patients in 3 different time ranges ( $<1$ year: $11.3 \pm 1.9$ vs. $8.5 \pm 2.8 \%$ (males vs. females); $1-5$ years: $12.4 \pm 1.0$ vs. $9.3 \pm 1.3 \%$; $>5$ years: $12.8 \pm 1.1$ vs. $7.7 \pm$ $1.6 \%)$, nor after correlation of their crude dialysis time with CAD risk (males: $\mathrm{r}^{2}=0.004, \mathrm{p}=0.47$; females: $\mathrm{r}^{2}=$ $0.003, \mathrm{p}=0.65)$.

\section{Immunosuppressive Therapy and CAD Risk}

Immunosuppressive therapy consisted of tacrolimus $(n=134)$, cyclosporine $(n=80)$ or rapamycin $(n=12)$ in combination with mycophenolate mofetil $(\mathrm{n}=141)$ or azathioprine $(\mathrm{n}=17)$ and/or steroids. When comparing CAD risk in the two different immunosuppressive treatment groups with tacrolimus and cyclosporine no significant differences were found in our patient cohort [males: tacrolimus 11.9 ( $\pm 0.8 \%)$, cyclosporine 13.3 $( \pm 1.5 \%)$; females: tacrolimus $9.6( \pm 1.4 \%)$, cyclosporine 7.8 ( $\pm 1.4 \%)$ (fig. 2$)]$. 


\section{Discussion}

Compared to dialysis patients, a reduction of the rate of cardiac death after successful renal transplantation has been reported $[12,13]$. However, cardiovascular death is still a major problem after transplantation. The aim of the present study was to evaluate the occurrence of different traditional and nontraditional cardiovascular risk factors, the extent of treatment/control of modifiable factors as well as their contribution to CAD risk. The use of the estimated 10-year CAD risk score was intended to identify patients at low, medium or high CAD risk in our typical, unselected cohort of renal transplant recipients.

One main finding of the present study is that the control of modifiable cardiovascular risk factors in a single center cohort of renal transplant recipients in routine ambulatory follow-up on average 3-4 years post-transplant is suboptimal according to current guidelines. The analysis revealed that $47.2 \%$ of patients were hypertensive, $10.3 \%$ of patients still smoked, $39.4 \%$ of patients had total serum cholesterol concentrations above 200 $\mathrm{mg} / \mathrm{dl}$, and $19.7 \%$ of patients had diabetes mellitus. In a previous study from Halifax investigating patients $\sim 7$ years after renal transplantation similar findings have been reported: $27 \%$ of the patients had systolic blood pressure levels $>140 \mathrm{~mm} \mathrm{Hg}, 23 \%$ smoked, $61 \%$ had LDL cholesterol levels $>100 \mathrm{mg} / \mathrm{dl}$, and $30.0 \%$ had diabetes mellitus [14].

These data emphasize the need for increased efforts in order to improve control of cardiovascular risk factors in renal transplant recipients. Therefore, a further goal of our study was to perform an in-depth analysis of the 10 year-CAD risk by calculating the Framingham algorithm not only for the whole transplant patient population investigated, but also for clearly defined subgroups.

The algorithm developed by Wilson et al. [10] to predict CAD in patients without overt CAD was originally established in a population with mostly normal renal function, and therefore may not be applicable for renal transplant recipients. However, the Framingham risk score predicted CAD rather well in a large cohort of renal transplant recipients, showing only a tendency for underestimation of the true incidence of CAD [15]. Comparing a chronic kidney disease (CKD; mean GFR $52.3 \pm 7.5 \mathrm{ml} /$ min in males and $53.2 \pm 7.5 \mathrm{ml} / \mathrm{min}$ in females) cohort with the Framingham population, Weiner et al. [16] could show that the Framingham risk score underestimated the 10 -year cardiac event rate (13.9 vs. $20.7 \%$ in males and 4.8 vs. $9.7 \%$ in females). Notably, in male CKD patients increasing total cholesterol and blood pressure categories did not contribute to increased cardiac event rates (in contrast to what was observed in the Framingham cohort) [16]. However, the cohort of male CKD patients was rather small $(n=357)$ in this trial and these findings need to be confirmed in larger trials.

The estimated 10-year CAD risk is not only heavily influenced by the above mentioned modifiable cardiovascular risk factors, but also by factors that cannot be modified, i.e. age and sex. Comparing the age-adjusted 10 -year CAD rates with the results from Wilson et al. [10] in the Framingham study population, we could show nearly similar findings for hypertension (e.g. hypertension stage 2 in males: in our cohort CAD risk 18.7 vs. $20.9 \%$ in the Framingham population; in females 12.6 vs. $14.1 \%)$ and HDL-cholesterol ( $<35 \mathrm{mg} / \mathrm{dl} 13.9$ vs. $15.8 \%$ in males, 13.0 vs. $14.7 \%$ in females; $>60 \mathrm{mg} / \mathrm{dl} 5.2$ vs. $8.2 \%$ in males and 4.6 vs. $3.9 \%$ in females). Concerning LDLcholesterol levels, remarkable differences could be seen comparing our results with those of Wilson et al. [10]. The risk was much higher in transplanted females compared to females without a transplant (LDL-cholesterol $<130 \mathrm{mg} / \mathrm{dl} 8.3$ vs. $2.3 \%,>160 \mathrm{mg} / \mathrm{dl} 18.6$ vs. $10.6 \%$ ); in contrast in males a difference could be noted only in the low LDL-cholesterol group ( $<130 \mathrm{mg} / \mathrm{dl} 7.3$ vs. $11.4 \%$, $>160 \mathrm{mg} / \mathrm{dl} 17.3$ vs. $17.3 \%$ ). In another study Ducloux et al. [17] prospectively followed 344 renal transplant recipients, registered coronary events and analyzed cardiovascular risk factors. In this population age, male gender, smoking status diabetes mellitus, creatinine clearance, low HDL-cholesterol and high systolic blood pressure were significantly associated with cardiovascular events. These data support the clinical value of our calculations showing a significant increase in CAD risk with increasing age, hypertension, diabetes mellitus, smoking, low HDL-cholesterol and high LDL-cholesterol. According to our data, the 10-year CAD risk increases 2- to 3-fold with uncontrolled hypertension, 2- to 4 -fold with severe hypercholesterolemia, 1.5 - to 2.5 -fold when diabetes mellitus is present, and 1.5-fold with active smoking. In addition, 10-year CAD risk increases up to 10- to 30 -fold with each 10 years higher age and 1.5 -fold with male gender.

In the population of renal transplant recipients investigated by Ducloux et al. [17], impaired renal transplant function was significantly associated with a higher 10year CAD risk. In our study, we found no significant correlation between renal function and CAD risk, also if we categorize impaired renal transplant function our analysis only showed a trend for impaired renal function to be associated with higher 10-year CAD risk; significance 
was presumably missed due to the lower patient number in our study and an overall higher CAD risk in our cohort. However, this finding is nevertheless important, as Meier-Kriesche et al. [18] have shown that the rate of cardiovascular death more than doubles when serum creatinine concentrations are elevated to $2.6-4.0 \mathrm{mg} / \mathrm{dl}$ (as compared to serum creatinine concentrations $<1.5 \mathrm{mg} /$ dl). Interestingly, other time-dependent variables which are known to influence CAD risk such as time on dialysis or time after transplantation did also not correlate, though CAD risk tended to decrease slightly over time after transplantation and was lowest (n.s.) in the patient group with dialysis duration $<1$ year. The missing correlation might be due to the rather low number of patients studied, as well as the use of the Framingham CAD risk score which was developed in the general population and might not pick up the additional risk conferred by longer dialysis duration or impaired renal function.

In 'real life' the CAD risk could be even higher, since in a landmark report Kasiske et al. [15] have reported that the Framingham algorithm underestimates the true risk of CAD and that diabetes mellitus and smoking are especially important risk factors for CAD in renal transplant patients.

Interestingly, we could also see that treatment with statins lowers the risk for CAD significantly. Against this background, it seems unfortunate that in our cohort only $46.5 \%$ of male and $54.2 \%$ of female renal transplant recipients were on statin treatment. Statin treatment in renal transplant recipients is supported by a recent work from Soveri et al. [19] showing that it indeed reduces the risk for major cardiovascular events in renal transplant recipients.

The number of post-transplant active smokers in our center is lower than in another study, but still reaches $12.5 \%$ (vs. 23\% in Halifax [14]). Previously reported data from our center document that we find significantly more active smokers on the waiting list as compared to renal transplant recipients [20]. We had assumed that the dramatic change in health and personal situation and the fear of a premature graft loss were the reasons to stop smoking.

In summary, control of modifiable cardiovascular risk factors in a cohort of renal transplant recipients is suboptimal according to current guidelines, and blood pressure, age, hyperlipidemia, smoking and diabetes mellitus contribute as expected to the estimated CAD risk in kidney transplant recipients. Furthermore, estimated CAD risk appears to increase with increasing serum creatinine and to decrease with increasing time after transplantation. One possible explanation for the decreasing CAD risk after transplantation may be the reduction of immunosuppressive drugs occurring the longer time since transplantation has elapsed. Furthermore, besides survival bias, cardiovascular risk reduction by means of dietary and behavioral changes, as well as drug treatment may play a role.

\section{Disclosure Statement}

None.

\section{References}

1 Krämer BK, Böger C, Krüger B, Marienhagen J, Pietrzyk M, Obed A, Paczek L, Mack M, Banas B: Cardiovascular risk estimates and risk factors in renal transplant recipients. Transplant Proc 2005;37:868-870.

2 Levey AS, Beto JA, Coronado BE, Eknoyan G, Foley RN, Kasiske BL, Klag MJ, Mailloux LU, Manske CL, Meyer KB, Parfrey PS, Pfeffer MA, Wenger NK, Wilson PW, Wright JT Jr: Controlling the epidemic of cardiovascular disease in chronic renal disease: what do we know? What do we need to learn? Where do we go from here? National Kidney Foundation Task Force on Cardiovascular Disease. Am J Kidney Dis 1998;32:853-906.

3 Opelz G, Wujciak T, Ritz E: Association of chronic kidney graft failure with recipient blood pressure. Collaborative Transplant Study. Kidney Int 1998;53:217-222.
4 Cosio FG, Pesavento TE, Kim S, Osei K, Henry $M$, Ferguson RM: Patient survival after renal transplantation. IV. Impact of posttransplant diabetes. Kidney Int 2002;62: 1440-1446.

5 Kasiske BL, Klinger D: Cigarette smoking in renal transplant recipients. J Am Soc Nephrol 2000;11:753-759.

6 Kasiske BL: Cardiovascular disease after renal transplantation. Semin Nephrol 2000;20: 176-187.

7 Roodnat JI, Mulder PG, Zietse R, RischenVos J, van Riemsdijk IC, IJzermans JN, Weimar W: Cholesterol as an independent predictor of outcome after renal transplantation. Transplantation 2000;69:1704-1710.
-8 Sarnak MJ, Coronado BE, Greene T, Wang SR, Kusek JW, Beck GJ, Levey AS: Cardiovascular disease risk factors in chronic renal insufficiency. Clin Nephrol 2002;57:327-335.

-9 Krämer BK, Zülke C, Kammerl MC, Schmidt C, Hengstenberg C, Fischereder M, Marienhagen J: Cardiovascular risk factors and estimated risk for CAD in a randomized trial comparing calcineurin inhibitors in renal transplantation. Am J Transplant 2003;3: 982-987.

10 Wilson PW, D’Agostino RB, Levy D, Belanger AM, Silbershatz H, Kannel WB: Prediction of coronary heart disease using risk factor categories. Circulation 1998;97:18371847. 
11 Chobanian AV, Bakris GL, Black HR, Cushman WC, Green LA, Izzo JL Jr, Jones DW, Materson BJ, Oparil S, Wright JT Jr, Roccella EJ: The Seventh Report of the Joint National Committee on Prevention, Detection, Evaluation, and Treatment of High Blood Pressure: the JNC 7 report. JAMA 2003;289: 2560-2572.

-12 Meier-Kriesche HU, Schold JD, Srinivas TR, Reed A, Kaplan B: Kidney transplantation halts cardiovascular disease progression in patients with end-stage renal disease. Am J Transplant 2004;4:1662-1668.

-13 Jones DG, Taylor AM, Enkiri SA, Lobo P, Brayman KL, Keeley EC, Lipson LC, Gimple LW, Ragosta M: Extent and severity of coronary disease and mortality in patients with end-stage renal failure evaluated for renal transplantation. Am J Transplant 2009;9: 1846-1852.
14 Kiberd B, Keough-Ryan T, Panek R: Cardiovascular disease reduction in the outpatient kidney transplant clinic. Am J Transplant 2003;3:1393-1399.

15 Kasiske BL, Chakkera HA, Roel J: Explained and unexplained ischemic heart disease risk after renal transplantation. J Am Soc Nephrol 2000;11:1735-1743.

16 Weiner DE, Tighiouart $\mathrm{H}$, Elsayed EF, Griffith JL, Salem DN, Levey AS, Sarnak MJ: The Framingham predictive instrument in chronic kidney disease. J Am Coll Cardiol 2007;50:217-224.
17 Ducloux D, Kazory A, Chalopin JM: Predicting coronary heart disease in renal transplant recipients: a prospective study. Kidney Int 2004;66:441-447.

18 Meier-Kriesche HU, Baliga R, Kaplan B: Decreased renal function is a strong risk factor for cardiovascular death after renal transplantation. Transplantation 2003;75:12911295.

19 Soveri I, Abedini S, Holdaas H, Jardine A, Eriksson N, Fellström B: Metabolic syndrome and cardiovascular risk in renal transplant recipients: effects of statin treatment. Clin Transplant 2009;23:914-920.

$>20$ Banas MC, Banas B, Wolf J, Hoffmann U, Krüger B, Böger CA, Orth SR, Krämer BK: Smoking behaviour of patients before and after renal transplantation. Nephrol Dial Transplant 2008;23:1442-1446. 